\title{
Effect of continuous compression and 30:2 cardiopulmonary resuscitation on cerebral microcirculation in a porcine model of cardiac arrest
}

\author{
Lin Yang ${ }^{1}$, Shuo Wang ${ }^{2}$ and Chun-Sheng $\mathrm{Li}^{2^{*}}$
}

\begin{abstract}
Background: The effect of rescue breathing on neurologic prognosis after cardiopulmonary resuscitation (CPR) is controversial. Therefore, we investigated the cerebral microcirculatory and oxygen metabolism during continuous compression (CC) and 30:2 CPR (VC) in a porcine model of cardiac arrest to determine which is better for neurologic prognosis after CPR.
\end{abstract}

Methods: After 4 min of ventricular fibrillation, 20 pigs were randomised into two groups ( $n=10 /$ group) receiving CC-CPR or VC-CPR. Cerebral oxygen metabolism and blood flow were measured continuously using laser Doppler flowmetry. Haemodynamic data were recorded at baseline and $5 \mathrm{~min}, 30 \mathrm{~min}, 2 \mathrm{~h}$ and $4 \mathrm{~h}$ after restoration of spontaneous circulation (ROSC).

Results: Compared with the VC group, the mean cortical cerebral blood flow was significantly higher at 5 min ROSC in the CC group $(P<0.05)$, but the difference disappeared after that time point. Brain percutaneous oxygen partial pressures were higher, and brain percutaneous carbon dioxide partial pressures were lower, in the VC group from 30 min to $4 \mathrm{~h}$ after ROSC; significant differences were found between the two groups $(P<0.05)$. However, no significant difference of the cerebral oxygen extraction fraction existed between the two groups.

Conclusions: Inconsistency of systemic circulation and cerebral microcirculation with regard to blood perfusion and oxygen metabolism is common after CPR. No significant differences in cortical blood flow and oxygen metabolism were found between the CC-CPR and VC-CPR groups after ROSC.

Keywords: Brain ischemia, Microcirculation, Cardiopulmonary resuscitation, Laser Doppler flowmetry, Haemodynamics

\section{Introduction}

The recommendations of the 2010 American Heart Association (AHA) guidelines for cardiopulmonary resuscitation (CPR) are based on adequate chest compressions for a critical amount of blood flow to the brain and the ventilation necessary to achieve adequate gas exchange [1]. Some experimental studies concerning cardiac arrest (CA) have shown that, compared with 30:2 chest compression

\footnotetext{
* Correspondence: ysys2001@yeah.net

2Department of Emergency Medicine, Beijing Chao-Yang Hospital, Affiliated to Capital Medical University, No. 8, South Road of Worker's Stadium, Chaoyang District, Beijing 100020, China

Full list of author information is available at the end of the article
}

(VC), continuous compression (CC) presents a similar rate of recovery and better neurological prognosis in addition to no significant deterioration in blood gas parameters in the first 4-8 min of resuscitation [2,3]. In adults with out-of-hospital CA, rescue breathing does not improve survival and neurological prognosis [4-6]. According to the results of our previous study, in the first $12 \mathrm{~min}$ of $\mathrm{CPR}, \mathrm{CC}$ maintains a relatively better coronary perfusion pressure (CPP), $\mathrm{PaO}_{2}$ and global ventilation/perfusion than VC [7]. Interruption of chest compressions for rescue breathing resulted in a periodical interruption of vital organ perfusion and lower perfusion pressure at the beginning of each compression cycle [8]. However, other studies 
have demonstrated that rescue breathing with chest compression achieves a better prognosis than CC alone [9]. Additionally, the tidal volume achieved by $\mathrm{CC}$ was found to be practically limited, and the ventilation produced by $\mathrm{CC}$ was insufficient to achieve adequate gas exchange [10].

Cerebral blood flow and oxygen delivery are crucial for the capillary exchange beds and are closely related to the recovery of cerebral function after CPR. However, a difference in cerebral microcirculation and oxygen dynamics between CC-CPR and VC-CPR has not been reported. In the present study, we measured blood flow and oxygen delivery in the cerebral cortex to investigate differences in cerebral microcirculation between CCCPR and VC-CPR in a porcine model of CA.

\section{Methods}

The present study was conducted with the approval of the Animal Care and Use Committee of Chao-Yang Hospital, affiliated with Capital Medical University, in Beijing, China.

\section{Animal preparation}

Twenty male domestic pigs $(32 \pm 3 \mathrm{~kg})$ were used in this study. Anaesthesia was induced by intramuscular injection of midazolam $(0.5 \mathrm{mg} / \mathrm{kg})$, followed by ear vein injection of pentobarbital $(8 \mathrm{mg} / \mathrm{kg} / \mathrm{h})$ to maintain anaesthesia. A cuffed $6.5-\mathrm{mm}$ endotracheal tube was advanced into the trachea. Pigs were mechanically ventilated by a volumecontrolled ventilator (PB-7200; Nellcor Puritan Bennett Incorporated, Pleasanton, CA, USA) with room air using a tidal volume of $15 \mathrm{~mL} / \mathrm{kg}$ and a respiratory frequency of 12 breaths per minute. The positive end expiratory pressure (PEEP) was set to zero. The end-tidal partial pressure of carbon dioxide $\left(\mathrm{EtPCO}_{2}\right)$ was measured using an in-line infrared capnograph $\left(\mathrm{CO}_{2} \mathrm{SMO}\right.$ plus monitor; Respironics Incorporated, Pittsburgh, PA, USA). The respiratory frequency was adjusted to maintain $\mathrm{EtPCO}_{2}$ between 4.67 and $5.33 \mathrm{kPa}$ before induction of $\mathrm{CA}$ and after the return of spontaneous circulation (ROSC). The room temperature was adjusted to $26^{\circ} \mathrm{C}$. A Swan-Ganz catheter (7F; Edwards Lifesciences, Irvine, CA, USA) was inserted from the right femoral vein and flow-directed into the pulmonary artery to measure central venous pressure (CVP) and cardiac output (CO) by a Hewlett-Packard monitor (M1165; Hewlett-Packard, Palo Alto, CA, USA). An angiographic catheter was inserted from the femoral artery into the aortic arch for arterial blood pressure (ABP), lactic acid (Lac) and arterial blood gas analyses (GEM Premier 3000 Blood Gas Analyser, Instrumentation Laboratory, Bedford, MA, USA). Electrocardiography (ECG) was conducted with the Hewlett-Packard monitor too. Another catheter (3.8-F) was inserted into the left internal jugular vein and passed in a retrograde direction as far as possible toward the jugular bulb for blood sampling to measure jugular venous oxygen saturation $\left(\mathrm{SjO}_{2}\right)$. This technique was used to allow continuous blood flow in the vein after insertion of the catheter [11]. A 5-F pacing catheter was advanced from the right internal jugular vein into the right ventricle to induce ventricular fibrillation (VF) using a programmed electrical stimulation instrument (GY-600A; Kaifeng Huanan Instrument Limited Company, China). For continuous measurement of cerebral cortical blood flow, both parietal regions of the skull were initially exposed. A laser Doppler flow (LDF) probe (Periflux ${ }^{\circ}$ Laser-Doppler Flowmeter PF2B; Perimed, Stockholm, Sweden) was placed directly over the surface of the right parietal cortex through a burr hole $(1 \mathrm{~cm}$ anterior to the coronal suture and $1 \mathrm{~cm}$ lateral to the sagittal suture) [12]. The other side was prepared in the same manner for continuous measurement of $\mathrm{PaO}_{2}$ and $\mathrm{PaCO}_{2}$ of the cerebral cortex.

\section{Experimental protocol}

After surgery, pigs were allowed to acclimatise for 30 min to achieve stability. VF was induced by programmed electrical stimulation [13] and confirmed by ECG with the presence of significant hypotension. Ventilation was stopped, and the ventilator was disconnected from the endotracheal tube. After 4 min of untreated VF, all animals were randomised into two groups with 10 piglets each receiving CC-CPR or VC-CPR [7].

Compressions were performed 100 times/min in both groups. In the VC group, manual ventilation was undertaken twice during a 5-s pause between the two $30 \mathrm{com}$ pression cycles using a bag respirator with $300 \mathrm{~mL}$ of room air.

After five cycles of CPR, defibrillation (Smart Biphasic) was attempted using $150 \mathrm{~J}$ for the first attempt, followed by five cycles of CPR. A 10-s pause was interjected to analyse the rhythm and prepare for the next five cycles of CPR and defibrillation attempts. If an organised cardiac rhythm with a mean aortic pressure $\geq 60 \mathrm{mmHg}$ persisting for an interval $\geq 10$ min was present, the pigs were regarded to have undergone successful ROSC. Animals without ROSC after four attempted defibrillations were pronounced dead. After successful resuscitation, the pigs were mechanically ventilated using the same parameters as the baseline and then underwent a 4-h intensive care period in which Ringer's solution $(20 \mathrm{~mL} / \mathrm{kg} / \mathrm{h})$ was administered. The neurological outcomes of the animals were evaluated according to the swine cerebral performance categories (CPCs) at $24 \mathrm{~h}$ after ROSC as previously described [14]. The animals were then sacrificed using intravenous potassium chloride and an overdose of pentobarbital to observe the intact lungs. 


\section{Measurements}

The mean arterial pressure (MAP), CVP, CO, heart rate (HR), and ECG were recorded. Blood gas analyses of arterial and jugular venous blood were repeatedly performed at baseline, $5 \mathrm{~min}, 30 \mathrm{~min}, 2 \mathrm{~h}$ and $4 \mathrm{~h}$ after ROSC. CO was measured using the thermodilution method by injection of $4^{\circ} \mathrm{C}$ saline at the same time points. Systemic vascular resistance (SVR) was calculated by the Hewlett-Packard monitor.

The cerebral oxygen extraction fraction (OEF) was calculated using the following formula: $\mathrm{OEF}=\left(1-\mathrm{SjO}_{2} /\right.$ $\left.\mathrm{SaO}_{2}\right) \times 100 \%$.

Cortical cerebral blood flow (CCBF), brain percutaneous partial pressure of oxygen $\left(\mathrm{PbtO}_{2}\right)$ and brain percutaneous partial pressure of carbon dioxide $\left(\mathrm{PbtCO}_{2}\right)$ were recorded continuously throughout the experiments using the LDF probe. The mean CCBF of the 5 min period was calculated at baseline, $30 \mathrm{~min}, 2 \mathrm{~h}$ and $4 \mathrm{~h}$ after CPR. The percentage change of $\mathrm{CCBF}$ was calculated using the following formula: Percentage change of $\mathrm{CCBF}=(\mathrm{PU} 2-\mathrm{PU} 1) / \mathrm{PU} 1$, where PU 1 represented the cortical cerebral blood flow at baseline and PU 2 represented the cortical cerebral blood flow of the observing point. Hereafter, $\mathrm{CCBF}$ is used to indicate the percentage change of the cortical cerebral blood flow.

\section{Statistical analyses}

Multivariate ANOVA was used for comparing values between the $\mathrm{CC}$ group and $\mathrm{VC}$ group, and all variables were considered in a multivariate model and tested for significance. Repeated measures ANOVA was used to compare values at baseline, $5 \mathrm{~min}, 30 \mathrm{~min}, 2 \mathrm{~h}$ and $4 \mathrm{~h}$ after ROSC. The data were reported as the means \pm SD. $\mathrm{P}<0.05$ was considered statistically significant. The Statistical Package for Social Sciences (version 13.0; SPSS, Chicago, IL, USA) was used for statistical analyses.

\section{Results}

\section{Outcomes}

Nine pigs of each group received ROSC and survived for $4 \mathrm{~h}$, and there were no significant differences in shocks before ROSC, the duration of CPR before ROSC and $24 \mathrm{~h}$ survival between the two groups. The CPCs of the CC and $\mathrm{VC}$ groups were $2.99 \pm 1.1$ and $3.01 \pm 1.2$, respectively; no significant difference existed between the two groups.

\section{CCBF and oxygen dynamics}

Compared with the VC group, the mean CCBF was significantly higher after ROSC $5 \mathrm{~min}$ in the $\mathrm{CC}$ group $(\mathrm{P}<0.05)$. The mean CCBF subsequently decreased gradually $4 \mathrm{~h}$ after ROSC in both groups with no significant difference between the two groups (Table 1).

$\mathrm{PbtO}_{2}$ reached a minimum 5 min after ROSC, increased rapidly at $30 \mathrm{~min}$ and decreased gradually during the whole period after ROSC in both groups. $\mathrm{PbtO}_{2}$ was higher in the $\mathrm{VC}$ group than in the $\mathrm{CC}$ group, and significant differences were found between the two groups at 5 min, $2 \mathrm{~h}$ and $4 \mathrm{~h}$ after ROSC $(\mathrm{P}<0.05) . \mathrm{PbtCO}_{2}$ increased from 5 min to $4 \mathrm{~h}$ after ROSC. $\mathrm{PbtCO}_{2}$ was lower in the $\mathrm{VC}$ group, and a significant difference was found between the two groups at each time point after ROSC $(\mathrm{P}<0.05)$, whereas no significant difference in MV was found (Table 1). $\mathrm{PH}$ and $\mathrm{PaO}_{2}$ recovered at $2 \mathrm{~h}$ and $4 \mathrm{~h}$ after ROSC in both groups (Table 1), and no significant difference in $\mathrm{PaO}_{2}$ and $\mathrm{pH}$ was found between the two groups. $\mathrm{PaCO}_{2}$ was higher at $5 \mathrm{~min}$ and $30 \mathrm{~min}$ after ROSC in the CC group than in VC group (Table 1). The peak value of Lac appeared at $30 \mathrm{~min}$ after ROSC in both groups, and it was higher in the $\mathrm{CC}$ group at $30 \mathrm{~min}, 2 \mathrm{~h}$ and $4 \mathrm{~h}$ after ROSC than in the $\mathrm{VC}$ group $(\mathrm{P}<0.05)$.

\section{Haemodynamic data}

MAP was higher at 5 min after ROSC in the CC group than in the VC group. No significant difference was found from 30 min to $4 \mathrm{~h}$ after ROSC between the two groups. Cerebral OEF increased maximally at 5 min after ROSC in both groups and then declined to baseline. No significant differences were found between the two groups (Table 2). CVP recovered within $30 \mathrm{~min}$ after ROSC in both groups, whereas $\mathrm{CO}$ and SVR did not recover until $4 \mathrm{~h}$ after ROSC in both groups. No significant difference was found between the two groups (Table 2).

\section{Discussion}

The present study investigated microcirculation after CPR and found inconsistency in the systemic circulation and cerebral microcirculation with regard to blood perfusion. CCBF only increased at $5 \mathrm{~min}$ after ROSC, and this increase may have been the result of a transient high MAP and CO in early ROSC. Four hours after ROSC, MAP, CO and CVP had recovered, but the LDF of the parietal cerebral cortex decreased in both groups, demonstrating the inconsistency of the systemic circulation and the cerebral microcirculation with regard to blood perfusion after ROSC. A previous study reported that the delay in continuous multifocal brain hypoperfusion was most obvious 2-12 h after CA, and global cerebral blood flow was reduced to 44$60 \%$ of baseline. Local cerebral hypoperfusion includes "no flow", "trickle flow" and "low flow", which are scattered and significantly increase ischemia and damage to grey matter [15]. The heterogeneity of the cortical cerebral microcirculation may be a reason why better systemic circulation does not mean better cerebral microcirculation. Vasomotion may be another reason for the inconsistency of systemic circulation and cerebral microcirculation. Vasomotion may exacerbate blood flow and oxygen transport heterogeneity when 
Table 1 Cerebral cortical blood flow and oxygen metabolism of the two groups (mean \pm SD)

\begin{tabular}{|c|c|c|c|c|c|c|}
\hline & Group & Baseline & ROSC & ROSC & ROSC & ROSC \\
\hline & & & $5 \mathrm{~min}$ & $30 \mathrm{~min}$ & $2 \mathrm{~h}$ & $4 \mathrm{~h}$ \\
\hline \multicolumn{7}{|l|}{ CCBF (\%) } \\
\hline & $\mathrm{CC}$ & & $48 \pm 14^{a}$ & $-38 \pm 11^{d}$ & $-40 \pm 10^{d}$ & $-45 \pm 10^{d}$ \\
\hline & VC & & $38 \pm 11^{d}$ & $-43 \pm 11^{d}$ & $-44 \pm 10^{d}$ & $-50 \pm 12^{d}$ \\
\hline \multicolumn{7}{|l|}{$\mathrm{PbtO}_{2}(\mathrm{kPa})$} \\
\hline & CC & $9.5 \pm 1.3$ & $4.1 \pm 0.8^{\mathrm{a}, \mathrm{d}}$ & $8.6 \pm 1.2^{b, c}$ & $7.0 \pm 0.8^{a, d}$ & $6.1 \pm 0.8^{a, d}$ \\
\hline & VC & $9.8 \pm 1.2$ & $3.4 \pm 0.8^{d}$ & $10.0 \pm 1.2$ & $7.8 \pm 0.6^{d}$ & $6.8 \pm 0.8^{d}$ \\
\hline \multicolumn{7}{|c|}{$\mathrm{PbtCO}_{2}(\mathrm{kPa})$} \\
\hline & CC & $5.3 \pm 0.8$ & $5.7 \pm 0.8^{\mathrm{a}}$ & $5.2 \pm 0.8^{b}$ & $5.3 \pm 0.6^{b}$ & $5.5 \pm 0.5^{a}$ \\
\hline & VC & $5.3 \pm 0.5$ & $5.3 \pm 0.7$ & $4.1 \pm 0.6^{d}$ & $4.6 \pm 0.8^{c}$ & $5.1 \pm 0.5$ \\
\hline \multicolumn{7}{|l|}{$\mathrm{PaO}_{2}(\mathrm{kPa})$} \\
\hline & $\mathrm{CC}$ & $11.7 \pm 0.9$ & $6.9 \pm 0.6^{d}$ & $7.3 \pm 0.6^{d}$ & $9.6 \pm 0.9^{d}$ & $11.3 \pm 0.8$ \\
\hline & VC & $11.9 \pm 0.8$ & $6.5 \pm 0.9^{d}$ & $7.0 \pm 0.7^{d}$ & $9.8 \pm 0.8^{d}$ & $11.7 \pm 0.6$ \\
\hline \multicolumn{7}{|l|}{$\mathrm{PaCO}_{2}(\mathrm{kPa})$} \\
\hline & CC & $5.8 \pm 0.6$ & $5.7 \pm 0.4^{b}$ & $5.8 \pm 0.6^{b}$ & $6.0 \pm 0.6$ & $6.2 \pm 0.7$ \\
\hline & VC & $5.9 \pm 0.7$ & $5.1 \pm 0.4^{d}$ & $4.5 \pm 0.4^{d}$ & $5.8 \pm 0.5$ & $6.1 \pm 0.5$ \\
\hline \multicolumn{7}{|l|}{$\mathrm{PH}$} \\
\hline & $\mathrm{CC}$ & $7.43 \pm 0.03$ & $7.33 \pm 0.06^{d}$ & $7.35 \pm 0.05^{d}$ & $7.42 \pm 0.04$ & $7.44 \pm 0.03$ \\
\hline & $\overline{V C}$ & $7.44 \pm 0.04$ & $7.35 \pm 0.06^{d}$ & $7.35 \pm 0.04^{d}$ & $7.43 \pm 0.03$ & $7.45 \pm 0.04$ \\
\hline \multicolumn{7}{|c|}{ Lac (mmol/L) } \\
\hline & CC & $2.03 \pm 0.55$ & $5.15 \pm 0.58^{d}$ & $8.09 \pm 1.19^{a, d}$ & $6.54 \pm 0.70^{b, d}$ & $4.09 \pm 0.72^{\mathrm{a}, \mathrm{d}}$ \\
\hline & $\overline{V C}$ & $1.92 \pm 0.58$ & $5.36 \pm 0.83^{d}$ & $7.26 \pm 1.12^{d}$ & $5.55 \pm 0.86^{\mathrm{d}}$ & $3.55 \pm 0.92^{d}$ \\
\hline \multicolumn{7}{|l|}{ MV (L/min) } \\
\hline & $\mathrm{CC}$ & $4.5 \pm 0.1$ & $5.6 \pm 0.6^{d}$ & $4.9 \pm 0.4$ & $4.8 \pm 0.3$ & $4.8 \pm 0.3$ \\
\hline & VC & $4.4 \pm 0.1$ & $5.3 \pm 0.5^{d}$ & $4.8 \pm 0.3$ & $4.8 \pm 0.3$ & $4.8 \pm 0.2$ \\
\hline
\end{tabular}

a. $p<0.05,{ }^{b} . p<0.01$ vs. the VC group; ${ }^{c} . p<0.05,{ }^{d} . p<0.01$ vs. the baseline.

ROSC: restoration of spontaneous circulation, CC: continuous compression group, VC: 30:2 cardiopulmonary resuscitation group, CCBF: cerebral cortical blood flow (percent change of $\mathrm{PU}, \mathrm{PU}$ : cortical cerebral blood flow), $\mathrm{PbtO}_{2}$ : cerebral cortical partial pressure of oxygen, $\mathrm{PbtCO}_{2}$ : cerebral cortical partial pressure of carbon dioxide, Lac: lactic acid, MV: minute volume.

hypoxia begins, thereby increasing oxygen consumption in the tissue of certain areas [16].

LDF is an appropriate method for continuous measurement of blood flow in the brain; however, blood flow measured using the LDF method shows variability among animals and even within the same animal. The variability is related to the heterogeneity of the brain microcirculation in addition to the temporal and spatial variations of the microcirculation. We used the percentage change in the mean CCBF with respect to baseline values; thus, temporal and spatial variability was reduced, and microcirculation-influenced factors such as cardiac and respiratory cycles and variability in neural activity were controlled for $[17,18]$.

Oxygen delivery mainly depends on local tissue microcirculation parameters, such as tissue $\mathrm{PCO}_{2}, \mathrm{PO}_{2}$, local metabolic byproducts, microcirculatory vasomotion and essential ventilation [16]. $\mathrm{PbtO}_{2}$ monitoring is one of the most reliable methods of cerebral oxygen monitoring, which can directly obtain brain tissue oxygen match and metabolic indices. It is a golden standard of therapeutic evaluation [19]. Former research reported $\mathrm{PbtO}_{2}$ could predict the mortality and disability rate of craniocerebral injury patients [20], which independently associated with the poor prognosis [21,22]. It could be a bedside auxiliary monitoring to determine brain dead.

In our study, $\mathrm{CCBF}$ was higher in the $\mathrm{CC}$ group at 5 min after ROSC, which resulted in better cerebral $\mathrm{PbtO}_{2}$. Subsequently, CCBF declined during the few hours after ROSC. The reasons for the sharper decrease of $\mathrm{PbtO}_{2}$ and higher $\mathrm{PbtCO}_{2} 5 \mathrm{~min}$ after ROSC in the CC group may include insufficient ventilation and transportation of oxygen to local tissues together with accumulation of carbon dioxide, which consequently resulted in anaerobic glycolysis because no significant differences of MV were found between the two groups. Thus, the level of Lac was higher in the CC group. Maintaining only minimum air flow by gasping and passive ventilation through compressiondecompression of the chest is not sufficient for metabolism in the brain [2,3]. However, rescue breathing may 
Table 2 Haemodynamics of the two groups (mean \pm SD)

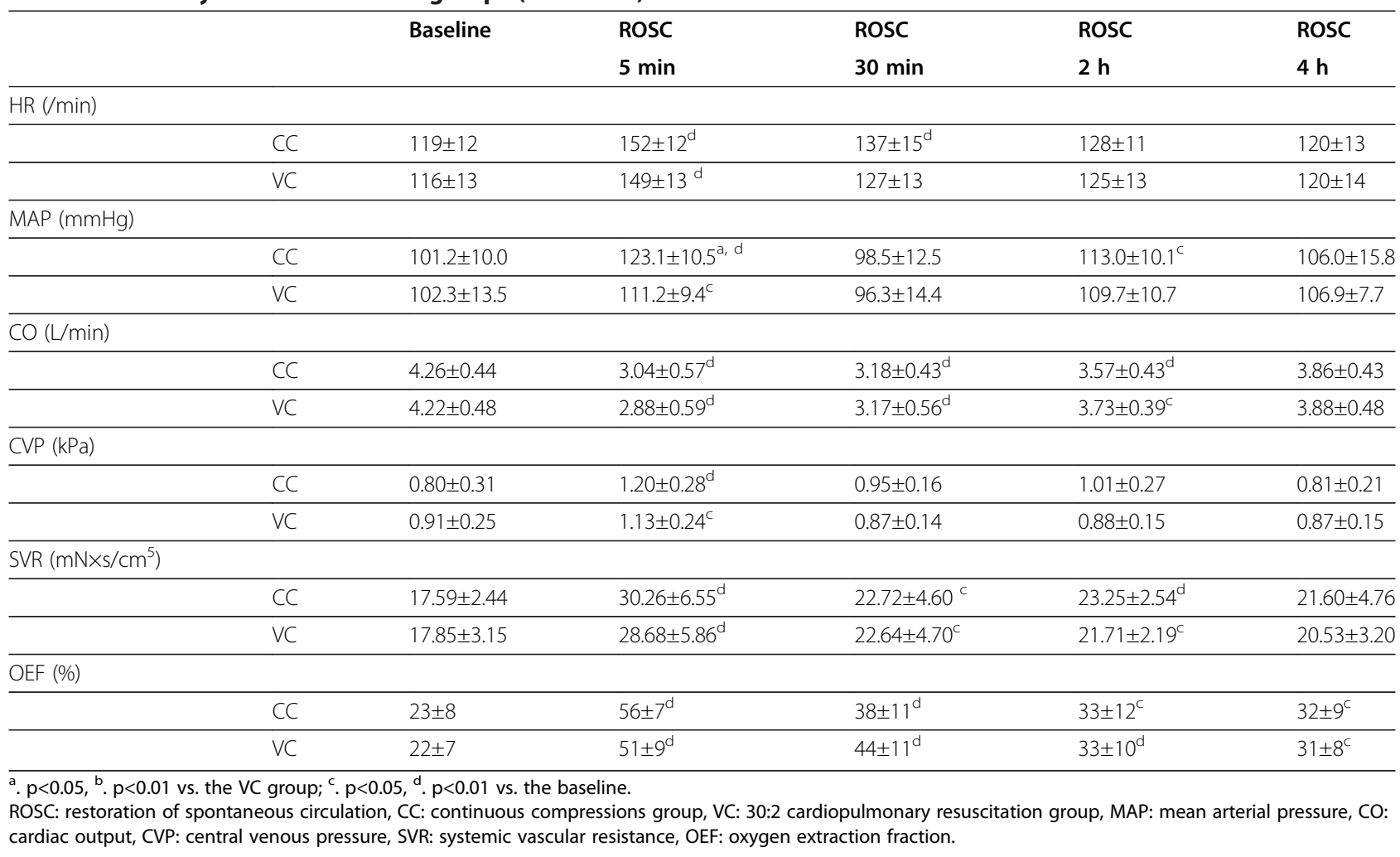

decrease the dead space after ROSC because of reduced atelectasis by positive pressure ventilation [23]. Because $\mathrm{EtPCO}_{2}$ was constant, the smaller gap between $\mathrm{PaCO}_{2}$ and $\mathrm{EtPCO}_{2}$ in the $\mathrm{VC}$ group may have resulted from lower dead space. Another mechanism may be the higher CCBF of the CC group during the initial stages of reperfusion, which can exacerbate neuronal injury through production of free radicals and mitochondrial injury [24,25].

In the $\mathrm{CC}$ group, $\mathrm{Lac}$ and $\mathrm{PbtCO}_{2}$ were maintained at a high level. Serious acidosis may prevent automatic adjustment of the cerebrovascular system, which could explain why CC-CPR provides better systemic circulation but does not result in better blood flow in the cerebral microcirculation and cortical oxygen delivery in the late phase after ROSC. Even with normal blood flow, most of the tissue may be poorly supplied [26]. Acidosis would worsen the central ischemia and hypoxia, producing a vicious circle after CPR. The consistent high level of Lac may result in low transport of oxygen in the $\mathrm{CC}$ group. SVR increased during the $4 \mathrm{~h}$ after ROSC in both groups, possibly because of peripheral vascular contraction to support the oxygen supply of the brain after CPR. CC-CPR may not alter microvascular smooth muscle tone and may thus not redistribute blood within the microvascular bed, in contrast to VC-CPR.

We also monitored cerebral OEF, which is an indicator of global cerebral oxygen uptake. There were no significant differences in OEF between the two groups during the $4 \mathrm{~h}$ after ROSC; there was an extremely high rate of OEF in both groups. One possible explanation may be that cerebral vessels dilate because of increased $\mathrm{PaCO}_{2}$ after CPR, thus leading to increased availability of oxygen in brain tissue [27].

\section{Study limitations}

The holes created in the parietal bone during craniotomy could influence the intracranial pressure; however, we did not record intracranial pressure in the present study. Intracranial pressure influences cerebral perfusion and the adjustment of the microcirculation. Detecting cerebral hypoxic-ischaemic events after CPR is difficult, particularly in parenchymal tissues such as the brain. The metabolism of the microcirculation and tolerance to anoxia are inconsistent in different brain regions. In the present study, the parietal cortex was chosen for detection of CCBF. Because both groups experienced the same proto$\mathrm{col}$, these biases do not influence our conclusions.

\section{Conclusions}

Inconsistency of the systemic circulation and cerebral microcirculation with regard to blood perfusion and oxygen metabolism is common after CPR. Both CC-CPR and $\mathrm{VC}-\mathrm{CPR}$ have the same prognosis. VC-CPR presents better $\mathrm{PbtO}_{2}$ and $\mathrm{PbtCO}_{2}$ at 5 min after ROSC, although no significant differences in $\mathrm{CCBF}$ and oxygen metabolism after CPR were found between CC-CPR and VC-CPR. 


\section{Key messages}

Cerebral blood flow and oxygen delivery are crucial for the capillary exchange beds and are closely related to the recovery of cerebral function after CPR.

Inconsistency between the macrocirculation and cerebral microcirculation is observed after CPR following cardiac arrest.

Both CC-CPR and VC-CPR present the same prognosis.

VC-CPR presents better $\mathrm{PbtO}_{2}$ and $\mathrm{PbtCO}_{2}$ after ROSC.

There are no significant differences in cortical blood flow and oxygen metabolism after CPR between CC-CPR and VC-CPR.

\footnotetext{
Abbreviations

CPR: Cardiopulmonary resuscitation; CA: Cardiac arrest; VC: 30:2 chest compression; CC: Continuous compression; CPP: Coronary perfusion pressure; EtPCO $\mathrm{C}_{2}$ : End-tidal partial pressure of carbon dioxide; ROSC: Return of spontaneous circulation; CVP: Central venous pressure; CO: Cardiac output; ABP: Arterial blood pressure; Lac: Lactic acid; ECG: Electrocardiography; $\mathrm{SjO}_{2}$ : Jugular venous oxygen saturation; VF: Ventricular fibrillation; LDF: Laser Doppler flow; CPC: Cerebral performance category; MAP: Mean arterial pressure; HR: Heart rate; SVR: Systemic vascular resistance; OEF: Cerebral oxygen extraction fraction; CCBF: Cortical cerebral blood flow; $\mathrm{PbtO}_{2}$ : Percutaneous partial pressure of oxygen; $\mathrm{PbtCO}_{2}$ : Percutaneous partial pressure of carbon dioxide.
}

\section{Competing interests}

The authors declare that they have no competing interests. The manuscript, including related data, figures and tables, has not been published previously and is not under consideration elsewhere.

\section{Authors' contributions}

LY: conception and design of the research, drafting of the manuscript and revising it critically for important intellectual content; SW: acquisition, analysis and interpretation of data; C-SL: giving final approval of the version to be published. All authors read and approved the final manuscript.

\section{Acknowledgments}

This study was supported by the National Natural Science Foundation of China (No. 30972863). We also thank Dr. Xian-Fei Ji and Zhi-Yun Su, who provided technological support for this study.

\section{Author details}

${ }^{1}$ Hyperbaric Oxygen Department, Beijing Chao-Yang Hospital, Affiliated to Capital Medical University, Beijing 100020, China. ${ }^{2}$ Department of Emergency Medicine, Beijing Chao-Yang Hospital, Affiliated to Capital Medical University, No. 8, South Road of Worker's Stadium, Chaoyang District, Beijing 100020, China.

Received: 24 September 2012 Accepted: 10 July 2013

Published: 12 July 2013

\section{References}

1. Committee ECC: Subcommittees and Task Forces of the American Heart Association: 2005 American Heart Association guidelines for cardiopulmonary resuscitation and emergency cardiovascular care. Circulation 2005, 112(Suppl):IV1-IV203.

2. Ewy GA, Zuercher M, Hilwig RW, Sanders AB, Berg RA, Otto CW, Hayes MM, Kern KB: Improved neurological outcome with continuous chest compressions compared with 30:2 compressions- to-ventilations cardiopulmonary resuscitation in a realistic swine model of out-ofhospital cardiac arrest. Circulation 2007, 116(22):2525-2530

3. Kern KB, Hilwig RW, Berg RA, Ewy GA: Efficacy of chest compression- only BLS CPR in the presence of an occluded airway. Resuscitation 1998, 39(3):179-188

4. SOS-KANTO Study Group: Cardiopulmonary resuscitation by bystanders with chest compression only (SOS-KANTO): an observational study. Lancet 2007, 369(9565):920-926.
5. Iwami T, Kawamura T, Hiraide A, Berg RA, Hayashi Y, Nishiuchi T, Kajino K, Yonemoto N, Yukioka H, Sugimoto H, Kakuchi H, Sase K, Yokoyama $H_{\text {, }}$ Nonogi $\mathrm{H}$ : Effectiveness of bystander-initiated cardiac-only resuscitation for patients with out-ofhospital cardiac arrest. Circulation 2007, 116(25):2900-2907

6. Ong ME, Ng FS, Anushia P, Tham LP, Leong BS, Ong VY, Tiah L, Lim SH, Anantharaman $\mathrm{V}$ : Comparison of chest compression only and standard cardiopulmonary resuscitation for outof-hospital cardiac arrest in Singapore. Resuscitation 2008, 78(2):119-126.

7. Wang S, Li C, Ji X, Yang L, Su Z, Wu J: Effect of continuous compressions and 30:2 cardiopulmonary resuscitation on global ventilation/perfusion values during resuscitation in a porcine model. Crit Care Med 2010, 38(10):2024-2030.

8. Assar D, Chamberlain D, Colquhoun M, Donnelly P, Handley AJ, Leaves S, Kern KB: Randomized controlled trials of staged teaching for basic life support: 1. Skill acquisition at the bronze stage. Resuscitation 2000, 45(1):7-15.

9. Iglesias JM, López-Herce J, Urbano J, Solana MJ, Mencía S, Del Castillo J: Chest compressions versus ventilation plus chest compressions in a pediatric asphyxial cardiac arrest animal model. Intensive Care Med 2010, 36(4):712-716

10. Chandra NC, Gruben KG, Tsitlik JE, Brower R, Guerci AD, Halperin HH, Weisfeldt ML, Permutt S: Observations of ventilation during resuscitation in a canine model. Circulation 1994, 90(6):3070-3075.

11. Chai PJ, Skaryak LA, Ungerleider RM, Greeley WJ, Kern FH, Schulman SR, Hansell DR, Auten RL, Mahaffey SF, Meliones JN: Jugular ligation does not increase intracranial pressure but does increase bihemispheric cerebral blood flow and metabolism. Crit Care Med 1995, 23(11):1864-1871.

12. Carter LP: Surface monitoring of cerebral cortical blood flow. CerebrovasC Brain Metab Rev 1991, 3(3):246-261.

13. Hamer AW, Karagueuzian HS, Sugi K, Zaher CA, Mandel WJ, Peter T: Factors related to the induction of ventricular fibrillation in the normal canine heart by programmed electrical stimulation. J Am Coll Cardiol 1984, 3(3):751-759.

14. Berg RA, Sanders AB, Kern KB, Hilwig RW, Heidenreich JW, Porter ME, Ewy $G A$ : Adverse hemodynamic effects of interrupting chest compressions for rescue breathing during cardiopulmonary resuscitation for ventricular fibrillation cardiac arrest. Circulation 2001, 104(20):2465-2470.

15. Sterz $F$, Leonov $Y$, Safar $P$, Johnson D, Oku K, Tisherman SA, Latchaw R, Obrist W, Stezoski SW, Hecht S: Multifocal cerebral blood flow by Xe-CT and global cerebral metabolism after prolonged cardiac arrest in dogs: Reperfusion with open-chest CPR or cardiopulmonary bypass. Resuscitation 1992, 24(1):27-47.

16. Anderson CM, Nedergaard M: Astrocyte-mediated control of cerebral microcirculation. Trends Neurosci 2003, 26(7):340-344.

17. Thorén A, Nygren A, Houltz E, Ricksten SE: Cardiopulmonary bypass in humans- jejunal mucosal perfusion increases in parallel with wellmaintained microvascular hematocrit. Acta Anaesthesiol Scand 2005, 49(4):502-509.

18. Goldman D, Popel S: A computational study of the effect of vasomotion on oxygen transport from capillary networks. J theor Biol 2001 209(2):189-199.

19. Bhatia A, Gupta AK: Neuromonitoring in the intensive care unit. II. Cerebral oxygenation monitoring and microdialysis. Intensive Care Med 2007, 33(8):1322-1328

20. Narotam PK, Morrison JF, Nathoo N: Brain tissue oxygen monitoring in traumatic brain injury and major trauma: outcome analysis of a brain tissue oxygen- directed therapy. J Neurosurg 2009, 111(4):672-682.

21. Figaji AA, Fieggen AG, Argent AC, Leroux PD, Peter JC: Does adherence to treatment targets in children with severe traumatic brain injury avoid brain hypoxia? A brain tissue oxygenation study. Neurosurgery 2008, 63(1):83-92.

22. Smith ML, Counelis GJ, Maloney-Wilensky E, Stiefel MF, Donley K, LeRoux PD: Brain tissue oxygen tension in clinical brain death: a case series. Neurol Res 2007, 29(7):755-759.

23. Wang S, Wu JY, Guo ZJ, Li CS: Effect of rescue breathing during cardiopulmonary resuscitation on lung function after restoration of spontaneous circulation in a porcine model of prolonged cardiac arrest. Crit Care Med 2013, 41(1):102-110.

24. Vereczki V, Martin E, Rosenthal RE, Hof PR, Hoffman GE, Fiskum G: Normoxic resuscitation after cardiac arrest protects against hippocampal oxidative 
stress, metabolic dysfunction, and neuronal death. J Cereb Blood Flow Metab 2006, 26(6):821-835.

25. Richards EM, Fiskum G, Rosenthal RE, Hopkins I, McKenna MC: Hyperoxic reperfusion after global ischemia decreases hippocampal energy metabolism. Stroke 2007, 38(5):1578-1584.

26. Kislukhin W: Regulation of oxygen consumption by vasomotion. Math Biosci 2004, 191(1):101-108.

27. Verweij BH, Amelink GJ, Muizelaar JP: Current concepts of cerebral oxygen transport and energy metabolism after severe traumatic brain injury. Prog Brain Res 2007, 161:111-124.

doi:10.1186/1757-7241-21-55

Cite this article as: Yang et al:: Effect of continuous compression and $30: 2$ cardiopulmonary resuscitation on cerebral microcirculation in a porcine model of cardiac arrest. Scandinavian Journal of Trauma,

Resuscitation and Emergency Medicine 2013 21:55.

\section{Submit your next manuscript to BioMed Central and take full advantage of:}

- Convenient online submission

- Thorough peer review

- No space constraints or color figure charges

- Immediate publication on acceptance

- Inclusion in PubMed, CAS, Scopus and Google Scholar

- Research which is freely available for redistribution 